\title{
Construction shielding design for medical X-ray imaging equipment
}

\author{
Seyed Ali Rahimi \\ Health Sciences Research Center, Mazandaran University of Medical Sciences, Kilometer 18 Khazarabad Road, P.O.BOX:48175-1553, Sari, \\ Iran
}

\section{Email address: \\ Rahimi201@yahoo.com}

\section{To cite this article:}

Seyed Ali Rahimi. Construction Shielding Design for Medical X-Ray Imaging Equipment. American Journal of Physics and Applications. Vol. 2, No. 5, 2014, pp. 104-107. doi: 10.11648/j.ajpa.20140205.11

\begin{abstract}
There are analytic methods for designing protective barriers however, they lack sufficient efficiency and considering the NCRP (National Council on Radiation Protection and measurements) reports, designing mechanical protective barrier in order to protect the initial x-ray radiation and absorption of the ray quality of such radiation is different. In this study, computer software was designed to calculate the needed barrier with high accuracy. For proper determination of thickness of the protective barrier, relevant information about curves of radiation weakness, dose limit and other items should be entered. This program was done in windows and designed in such a way that the operator works easily, flexibility of the program is acceptable and its accuracy and sensitivity is high. Meanwhile sometimes shielding is more than what required which lacks technical standards and cost effectiveness. When the application index is contrasting zero, thickness of NCRP49 calculation is about $20 \%$ less than the calculated rate done by the method of this study. The multi radiation sources in a single room are considered and non guaranteed radiation of NCRP hypothesis is removed. Difference between the theoretical and calculated rates of this method is $X^{2}=10^{-5}$ which indicates accuracy and high efficiency of this software.
\end{abstract}

Keywords: Shielding, Diagnostic X-Ray, Attenuation Curve, Building Materials

\section{Introduction}

These methods reassess shielding calculations in X-ray areas with respect to the methodology of the calculation of the barrier thickness and the number of sources consider in the area. Thus, they generate an overall solution for the cases met at the medical radiation structural design [1].

This report provides an extension of an existing method for the calculation of the barrier thickness required to reduce the three types of radiation exposure emitted from the source, the primary, secondary and leakage radiation, to a specified weekly design limit MPD (Maximum Permissible Dose). Because each of these three types of radiation is of different beam quality, having different shielding requirements, NCRP49 (National Council on Radiation Protection and measurements) has provided means to calculate the necessary protective barrier thickness for each type of radiation individually [2].

However, this report (NCRP49) provides little guidance for the contribution of each of the three types of radiation to the barrier thickness requirement. The medical physicist have to estimate which components of the field are most important to be shielded and how they are to combine, if more than one component is significant to generate a single shielding requirement. In questionable situations, multiple half-value layers (HVLs) of material recommended to be added; by the general "add one half value layer (HVL)" approximation of NCRP49. Since the specified half value layers are those measured at high attenuation, the resultant barrier may be unnecessarily thick $[3,4]$.

Additionally, barrier requirements specified using the techniques stated at NCRP49, show enormous variations among users. Part of the variations is due to different assumptions made regarding the use of the examined room and the characteristics of adjoining space. Many of the differences result from the difficulty of accurately relating information from the calculations to graphs and tables involved in the calculation process specified by this report. Moreover, the latest technological developments such as mammography are not addressed and attenuation data for three-phase generators, that are most widely used today, is not provided $[4,5]$. 
The design and shielding barriers in diagnostic X-ray departments generally follows the ALARA principle. That means that, in practice, the exposure levels are kept "as low as reasonably achievable", taking into account consideration economical and technical factors. Additionally, the calculation of barrier requirements includes many uncertainties (the workload, the actual $\mathrm{kVp}$ used and other items) $[6,7,8]$.

\section{Materials and Methods}

a. Model Proposed

Some of the variations among shielding requirements determined by various users are resulted from the difficulty of accurately relating information from the calculations, graphs and tables involved in the computation process specified by the NCRP Report 49[2,9]. In order to achieve simplification, Archer proposed a three-parameter model that accurately fit the published transmission data for lead in NCRP49. He also described an approach to account for the contribution of both scatter and leakage radiation [1].

b. Model Description

Each attenuation curve from NCRP49 Appendix D can be described by a curvilinear function, which increases rapidly at small values of lead shielding and then becomes horizontal at the large thickness.

Such behavior was found by Archer integrated to obtain a mathematical representation:

$$
K=K_{0}\left[(1+\beta / \alpha) e^{+\alpha \gamma \gamma}-\beta / \alpha\right]^{-1 / \gamma}
$$

Where $\mathrm{K}$ is the number of Roentgens per mA-min per week at $1 \mathrm{~m}, \mathrm{~K} 0$ is the value of $\mathrm{K}$ with no lead in the beam, $\mathrm{X}$ is the thickness of lead in $\mathrm{mm}$ and $\alpha, \beta, \gamma$ were determined by the use of a modified non-linear least square program $[1,7,8]$.

Application of the model to primary barrier calculations is straight forward since if equation is set equal to the model, the resulting expression can be solved for the thickness of lead required to reduce the weekly exposure at Dpri(Primary dose) to the maximum permissible exposure $[1,2,10]$.

Simplification of the NCRP 49 methods for determining secondary barriers is more difficult since both leakage and scattered radiation must be considered. The scattered radiation barrier is calculated from the equation described at NCRP 49 model. Therefore, setting this equation equal to that of (1), the required barrier thickness to protect for scatter radiation can be calculated[10,11].. For leakage radiation and in order to simplify the procedure for computer calculation, the required number of HVLs (Half value layer) can be related to the transmission factor BLx from the equation:

$$
B L \mathrm{x}=\frac{P d_{\mathrm{sec}}^{2} \cdot 600 I}{W T}
$$

The leakage barrier thickness can then be determined:

$$
S_{L}=N \cdot H V L=\frac{-\ln \left\{\frac{P d_{\mathrm{sec}}^{2} \cdot 600}{W T}\right\}}{\ln 2} H V L
$$

The model and the simplification provided by equation (3) could be used to relate the thickness of barriers for leakage and scattered radiation to dsec(distance scatter) [1,12]. The actual exposure from leakage and scattered radiation at any value of dsec can also be determined for a specified barrier. This relation is essential in determining the "exact" secondary barrier thickness required to meet the design limits. The total exposure at a point of interest, Ptot(total exposure at a point), is found by solving equations NCRP and (3) for $\mathrm{P}$ and adding them:

$$
P_{\text {tot }}=P_{S}+P_{L}
$$

Where PL and PS are the contributions from leakage and scatter radiation respectively. Substitution yields:

$$
P_{t o t}=\frac{W T}{d_{\mathrm{sec}}^{e}}\left[\frac{\exp \left(-\frac{L n 2 . x}{H V L}\right)}{600 I}+\frac{a k_{u x}}{d_{s c a}^{2}(400 / F)}\right]
$$

The above equation is then solved to compute the appropriate thickness of material to make the sum of the calculated leakage and scatter exposures equal to the weekly exposure limit $[12,13]$.

\section{Results and Discussion}

Shielding requirements for a radiographic and a chest radiographic unit in combination in the same room. Realistic results. Workload considered being the half for each tube 500 $\mathrm{mA} \mathrm{min/week} \mathrm{for} \mathrm{Tube,} \mathrm{table} \mathrm{number} 1$ to 6 .

Figure (1) shows the excellent fit to the original curves obtained with the model based on the equation (1). For a given value of $\mathrm{K}$, no value of $\mathrm{X}$ (Thickness)found to differ by more than $0.03 \mathrm{~mm}$ from the original data.

Figure 1: Values generated by the mathematical model of equation (B.1) (open circles) closely approximate the attenuation curves from NCRP 49, Fig.1, Appendix D. (Taken from Archer et al. [1,14]).

One of the advantages of the model is that it provides a concise representation of many different attenuation curves. This greatly simplifies the task of designing a computer program to determine shielding requirements in Tehran University of Medical Sciences. Excellent agreement was found in the shielding requirements for primary barriers calculated by using the above mathematical three-parameter model and NCRP 49 methodology $[15,16]$.

Moreover, as it has been described analytically, the presented method allows greater accuracy in the computation of secondary barriers. This is due to the fact that the shielding thickness required to reduce the weekly exposure to the design limit, can be precisely determined with no use of the "Add one HVL" recommendation of NCRP 49, which results to over shielding [17]. 


\section{Conclusion}

In this study proper determination of required protective thickness for weakening of radiation to the permissible level is proposed. The multi radiation sources in a single room are considered and non guaranteed radiation of NCRP49 hypothesis is removed. Difference between the theoretical and calculated rates of this method is $\mathrm{X}^{2}=10^{-5}$ which indicates accuracy and high efficiency of this software [18].

Table 1. $\mathrm{I}=4 \mathrm{~mA}, 125 \mathrm{kVp}, 1000 \mathrm{~mA} \mathrm{~min} /$ week Radiographic Examinations

\begin{tabular}{llllll}
\hline Barrier & $\mathbf{P}(\mathbf{m S v} / \mathbf{w e e k})$ & Use factor, $\mathbf{U}$ & Dpri $(\mathbf{m})$ & Dsec $(\mathbf{m})$ & Dleak $(\mathbf{m})$ \\
\hline Floor & 0.02 & 1 & 2.0 & 1.2 & 2.0 \\
Ceiling & 0.02 & 0 & 0.0 & 1.8 & 1.0 \\
Barrier 1 & 0.02 & 0.5 & 2.1 & 1.3 & 2.0 \\
Barrier 2 & 0.12 & 0 & 0.0 & 3.0 & 3.8 \\
\hline
\end{tabular}

Table 2. Chest Radiographic Examinations $I=4 \mathrm{~mA}, 125 \mathrm{kVp}, 1000 \mathrm{~mA}$ min/week

\begin{tabular}{llllll}
\hline Barrier & $\mathbf{P}(\mathbf{m S v} /$ week $)$ & Use factor, $\mathbf{U}$ & Dpri $(\mathbf{m})$ & Dsec $(\mathbf{m})$ & Dleak $(\mathbf{m})$ \\
\hline Floor & 0.02 & 0 & 0.0 & 2.0 & 2.0 \\
Ceiling & 0.02 & 0 & 0.0 & 1.0 & 1.0 \\
Barrier 1 & 0.02 & 1 & 2.0 & 2.5 & 3.0 \\
Barrier 2 & 0.12 & 0 & 0.0 & 3.0 & 4.0 \\
\hline
\end{tabular}

Table 3. Comparison results between these calculated by NCRP 49 and that described in this proposed.

\begin{tabular}{|c|c|c|c|c|c|c|c|c|}
\hline \multirow{3}{*}{$\begin{array}{l}\text { Barrier } \\
\text { Floor }\end{array}$} & \multirow{3}{*}{$\begin{array}{l}\text { LEAD(mm) } \\
\text { NCRP } 49 \\
3.0\end{array}$} & \multicolumn{3}{|c|}{ Proposed method(mm) } & \multirow{3}{*}{$\begin{array}{l}\text { CONCRETE } \\
\text { NCRP49 (mm) } \\
260.0\end{array}$} & \multirow{2}{*}{\multicolumn{3}{|c|}{$\begin{array}{l}\text { Proposed method(mm) } \\
\text { Table Recp Grid\&cassette }\end{array}$}} \\
\hline & & \multicolumn{3}{|c|}{ Table Recp Grid\&cassette } & & & & \\
\hline & & 3.88 & 3.63 & 3.07 & & 280 & 257 & 208 \\
\hline Ceiling & 2.1 & 2.43 & - & - & 155.6 & 163 & - & - \\
\hline Barrier 1 & 2.7 & 3.53 & 3.30 & 2.77 & 240.0 & 258 & 235 & 191 \\
\hline Barrier 2 & 0.9 & .811 & - & - & 66.8 & 67.6 & & \\
\hline
\end{tabular}

Table 4. Chest Radiographic Examinations $1000 \mathrm{~mA}$ min/week for Tube

\begin{tabular}{llllllll}
\hline \multirow{2}{*}{ Barrier } & LEAD $(\mathbf{m m})$ & \multicolumn{2}{l}{ Proposed method $(\mathbf{m m})$} & \multicolumn{2}{l}{ CONCRETE } & \multicolumn{2}{l}{ Proposed method (mm) } \\
\cline { 2 - 8 } & NCRP 49 & \multicolumn{2}{l}{ Table Recp Grid\&cassette } & NCRP49 $(\mathbf{m m})$ & \multicolumn{2}{c}{ Table Recp Grid\&cassette } \\
\hline Floor & 2.0 & 1.77 & - & - & 148.2 & 120 & - \\
Ceiling & 2.6 & 2.37 & - & - & 192.6 & 158 & - \\
Barrier 1 & 3.0 & 3.69 & 3.44 & 2.78 & 260.0 & 250 & 226 \\
Barrier 2 & 0.9 & .651 & - & - & 66.8 & 52 & - \\
\hline
\end{tabular}

Table 5. Combination of radiographic and chest radiographic examinations in the same room, $1000 \mathrm{~mA}$ min/week for Tube

\begin{tabular}{|c|c|c|c|c|c|c|c|c|}
\hline \multirow{3}{*}{$\begin{array}{l}\text { Barrier } \\
\text { Floor }\end{array}$} & \multirow{3}{*}{$\begin{array}{l}\text { LEAD }(\mathbf{m m}) \\
\text { NCRP } 49 \\
3.3\end{array}$} & \multicolumn{3}{|c|}{ Proposed method (mm) } & \multirow{3}{*}{$\begin{array}{l}\text { CONCRETE } \\
\text { NCRP } 49(\mathbf{m m}) \\
260.0\end{array}$} & \multirow{2}{*}{\multicolumn{3}{|c|}{$\begin{array}{l}\text { Proposed method (mm) } \\
\text { Table Recp Grid\&cassette }\end{array}$}} \\
\hline & & \multicolumn{3}{|c|}{ Table Recp Grid\&cassette } & & & & \\
\hline & & 3.88 & 3.64 & 3.09 & & 280 & 257 & 209 \\
\hline Ceiling & 2.9 & 2.70 & - & - & 215.0 & 180 & - & - \\
\hline Barrier 1 & 3.3 & 3.93 & 3.68 & 3.08 & 282.4 & 274 & 250 & 204 \\
\hline Barrier 2 & 1.2 & .989 & - & - & 89.2 & 77.9 & - & - \\
\hline
\end{tabular}

Table 6. Combination of radiographic and chest radiographic examinations in the same room.

\begin{tabular}{llllllll}
\hline \multirow{2}{*}{ Barrier } & LEAD $(\mathbf{m m})$ & \multicolumn{2}{l}{ Proposed method $(\mathbf{m m})$} & \multicolumn{2}{l}{ CONCRETE } & \multicolumn{2}{c}{ Proposed method (mm) } \\
\cline { 2 - 9 } & NCRP 49 & \multicolumn{2}{c}{ Table Recp Grid\&cassette } & \multicolumn{2}{l}{ NCRP49 $(\mathbf{m m})$} & \multicolumn{2}{c}{ Table Recp Grid\&cassette } \\
\hline Floor & 3.3 & 3.57 & 3.33 & 2.78 & 260.0 & 261 & 237 \\
Ceiling & 2.9 & 2.4 & - & - & 215.0 & 160 & - \\
Barrier 1 & 3.3 & 3.62 & 3.54 & 2.78 & 282.4 & 254 & 244 \\
Barrier 2 & 1.2 & .739 & - & - & 89.2 & 60.6 & - \\
\hline
\end{tabular}


More realistic results. Workload considered being the half for each tube $500 \mathrm{~mA} \mathrm{min/week} \mathrm{for} \mathrm{Tube} \mathrm{[19].}$

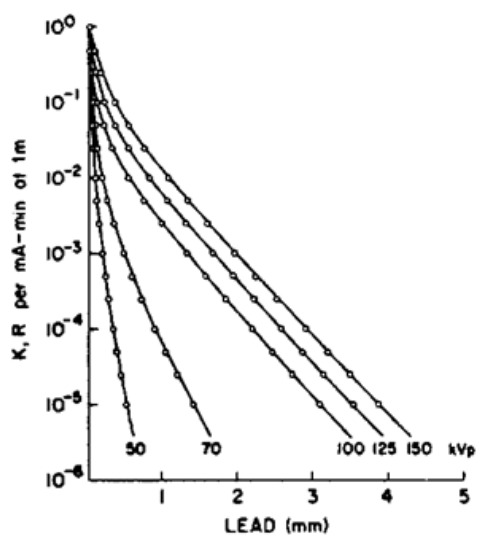

Figure 1. Values generated by the mathematical model of equation (B.1) (open circles) closely

Approximate the attenuation curves from NCRP 49, Fig.1, Appendix D. (Taken from Archer et al. [1]).

\section{References}

[1] Benjamin R. archer, T.R. fewell ,B. J. Conway and P.w. quinn "Attenuation properties of diagnostic x-ray shielding materials" Health physics Vol. 21, No.9. September, pp, 1499$1505,1994$.

[2] NCRP Report 49, " structural Shielding Design and evaluation for medical use of x-ray rays and gamma rays of energies up to $10 \mathrm{mev"}$, national council on radiation protection and measurements, 1976

[3] Edward L. Nickoloff and Eileen M. Donnelly"Use of gypsum drywall as shielding material for mammography" Health physics Vol.54, No.6,(June), pp. 465-468,1989.

[4] C. Maccia, M Benedittini and C. lefaure, f. fagnani "Doses to patients from diagnostic radiology in france" Health physics Vol.54, No.4, (April), pp. 397-340, 1988

[5] Stewart C.bushong and Sharon A .glaze "Radiographic workload and use factors for orthopedic facllties" Health physics Vol.44, NO.1, (January). Pp.53-59, 1983

[6] G.Panagiotakis, J. kandarakis, "Lecture notes on diagnostic radiology for the msc in European medical physics",1995.
[7] International commission radiological units ,"Quantities and units in radiation protection dosimetry ", ICRU Report 51.

[8] International commission on radiological protection, "1990 recommendations of the international commission on radiological protection," ICRP publication 60 .

[9] M.petrantonaki,C,kappas, E.P. Efstathopiulos, Y, theodorakos, GlPanagiotakis, "Calculating shielding requirements in diagnostic x-ray departments", August 1998

[10] ICRP Publication 26 (1977), "recommendations of the international commission on radiological protection".

[11] Seyed Ali Rahimi,EVALUATION of RADIOLOGY PERSONNEL PRACTICE OF Mazandaran UNIVERSITY OF MEDICAL SCIENCES HOSPITALS. QANTRM(2006)Organized by the ,IAEA- Vienna- Austria.

[12] Seyed Ali Rahimi, Study on the performance of recommended standards in the diagnostic radiology units of the hospitals affiliated to the Mazandaran University of Medical Scienc,Journal of X-Ray Science and Technology Amsterdam Ios press- 15(2007)57-63- Netherlands.

[13] Methé BM. Shielding design for a PET imaging suite: a case study. Health Phys. 2003 May; 84(5 Suppl):S83-8.

[14] Casanova AO, López N, Gelen A, Guevara MV, Díaz O, Cimino L, D'Alessandro K, Melo JC. Shielding analysis of the Microtron MT-25 bunker using the MCNP-4C code and NCRP Report 51. Radiat Prot Dosimetry. 2004;109(3):189-95.

[15] Fog LS, Cormack J. Mathematical modeling of the radiation dose received from photons passing over and through shielding walls in a PET/CT suite. Health Phys. 2010 Dec;99(6):769-79. doi: 10.1097/HP.0b013e3181e47a39.

[16] Fujita Y, Myojoyama A, Saitoh H. BREMSSTRAHLUNG AND PHOTONEUTRON PRODUCTION IN A STEEL SHIELD FOR 15-22-MEV CLINICAL ELECTRON BEAMS. Radiat Prot Dosimetry. 2014 May 12.

[17] Mori H, Koshida K, Ishigamori O, Matsubara K. A novel removable shield attached to $\mathrm{C}$-arm units against scattered $\mathrm{X}$ rays from a patient's side. Eur Radiol. 2014 Aug;24(8):1794-9.

[18] Colletti PM, Micheli OA, Lee KH. To shield or not to shield: application of bismuth breast shields. AJR Am J Roentgenol. 2013 Mar;200(3):503-7.

[19] Elschot M, de Wit TC, de Jong HW. The influence of selfabsorption on PET and PET/CT shielding requirements. Med Phys. 2010 Jun;37(6):2999-3007. 